\title{
The Effect of a Low-Level Laser in the Treatment of Glossopyrosis and Glossodinia
}

\author{
Ana Pejcic ${ }^{1}$, Ivan Minic ${ }^{2}$, Radmila Obradovic ${ }^{1}$, Marija Bradic ${ }^{2}$ \\ ${ }^{1}$ Department of Periodontology and Oral Medicine, University of Nis, Serbia, ${ }^{2}$ Department of Periodontology and Oral Medicine, \\ University of Nis, Serbia
}

\begin{abstract}
Introduction: Glossodinia and glossospyrosis is characterized by the appearance of symptoms of burning and pain. Sometimes these symptoms of tingling and pain in the tongue can occur even without any pathological changes in the oral cavity. Low-level lasers, used in the therapy of some oral diseases, showed a positive effect after use, and the aim of this paper was to examine whether the analgesic effect of low-level laser has an effect on the reduction of subjective symptoms of burning and pain in the tongue, as well as whether it affects the quality of life of a patient.

Material and Methods: The study included 45 patients who came to the Department of Oral Medicine and Periodontology of the Clinic for Dentistry, Faculty of Medicine, Nis. All of them had symptoms of burning and pain in the tongue. Twenty-six patients, randomly selected, in addition to symptomatic, also received low-level laser therapy to lose symptoms of burning and pain. A lowlevel laser KaVo MASTER lases, Biberach, Germany, was used, a wavelength being $980 \mathrm{~nm}$ with an output power of $0.2 \mathrm{~W}$ in continuous mode.

Results: Ten patients agreed that the low-level laser reduces the subjective feelings of the dinya and pyrosis. There were no side effects and all patients completed the treatment without interruption. In no case was there any worsening of the symptoms, while 4 patients did not report any improvement.

Conclusion: According to the results of this study it can be said that low-level lasers can be used as one of the therapeutic procedures in the treatment of Glossodynia and Glossopyrosis, as well as in improving the quality of life of patients with the same or similar problems.
\end{abstract}

Key Words: Glossodynia, Glossopyrosis, Low-level laser, Therapy

\section{Introduction}

The tongue is a powerful organ whose muscles stretch in three directions, allowing for its high mobility. It is connected with the bottom of the mouth and it is an important control factor in the elimination of many harmful noxious substances. Thanks to good inertia and blood flow, the tongue is able to detect the feeling of contact, pressure, warm and cold, as well as a special sense of taste. The well-developed sensory ability, due to the presence of a large number of receptors, also exhibits a protective feature, because of which it "examines" different substances in the oral cavity and has a strong tendency to remove anything foreign in the oral cavity.

Burning mouth syndrome (glossalgia, stomatodynia, stomatopyrosis, glossopyrosis, glossitis) is defined as a spontaneous syndrome of the presence of burning sensations, discomfort, pain, irritation or tingling of the tongue, lips or mouth, very often without any objective causes [1-3].

Glossopyrosis and glossodynia are characterized by the symptoms of burning and tingling of the tongue, most commonly on the top, the dorsal side and the lateral edges of the tongue [4,5]. Often these symptoms are associated with dryness and taste disorder. Pyrosis and dynias are very common, with a tendency to increase in the world, and more in women. People with glossopyrosis describe their problems as picturesque: burns, tingles, gathers, tighten, stabs, etc.

The ethological factors of this discomfort are many local (developmental anomalies, excessive smoking, alcohol consumption, inadequate conservative fillings, and prosthetics, etc.), but also general factors (anemia, diabetes, digestive tract disorders, etc.)[6,7]. True dynia and pyrosis (essential) are not accompanied by any changes in oral mucous membranes and occur in depression, anxiety, arteriosclerosis, cervical spondylosis, and neurohormonal imbalances. The prevalence of glossodynia and pyrosis is higher in women of middle age, in postmenopausal periods, which can also occur due to decreased level or cessation of estrogen formation. The relationship between the occurrence of this syndrome between women and men is from $3: 1$ to $16: 17$.

Patients usually wake up in the morning without any pain and symptoms, but during the day they increase to give a serious and unpleasant subjective feeling in the afternoon. Many patients suffer this condition for years, before visiting a doctor.

Diagnosis is easily established, based on anamnestic data, an objective examination of oral cavity and laboratory findings.

Therapy is complex and depends on etiology. It is mostly symptomatic with the use of anesthetics, antiseptics, antimycotics, sedatives, dietary nutrition, stimulation of the salvation of the saliva, and even with the application of artificial saliva $[8,9]$. Physical methods of treatment can also be used among the numerous methods of treatment of glossopyrosis and glossodynia [10].

Modern methods of laser prophylaxis and physiotherapy using the latest laser techniques are used to treat a large number of dental diseases, in the field of endodontics, surgery, child dentistry, periodontics, implantology, etc.

The use of lasers can significantly affect the sensitivity and immunity, and therefore is successfully used in the treatment 
of some oral diseases (herpes simplex, aphthae, etc.) in order to improve immunity. Laser light has a wide range of prophylactic and medicinal effects. Laser application reduces inflammation and swelling, normalizes microcirculation [11]. Laser radiation stimulates metabolism, accelerates wound healing, reduces the formation of scars after surgery, and others. In addition, the laser exhibits a myorelaxant, desensitizing, and analgesic effect [12].

Bearing in mind the above, the laser is used successfully in dentistry, especially in periodontology and in the treatment of mucosal mucous membrane disease. The laser can be used independently and together with methods of conservative, medication and surgical treatment [13].

In the cases of mucous membrane diseases in the oral cavity, a positive effect of the low-level laser was observed. In the treatment of herpes labialis, both herpetic and aphthous stomatitis, i.e. in all the changes that are manifested by an exudative type of inflammation, laser radiation contributes to the reduction of the inflammatory process and greatly speeds up epithelization. In all these cases, in addition to antiinflammatory and stimulating action, the laser also exhibits analgesic effect [14].

A special indication for the application of laser therapy is glossodynia and glossopyrosis as part of the symptoms of burning and painful sensations in the oral cavity.

The aim of this study was to investigate the analgesic effect of laser radiation in patients with glossopyrosis and glossodynia as an additional physical treatment method and assess the overall quality of life of these patients.

\section{Material and Methods}

All patients, 45 of them who participated in this study, reported to the Department of Oral Medicine and Periodontology of the Clinic for Dentistry at the Medical Faculty in Nis because of the presence of symptoms of burning and pain in the mouth. Patients were from 25 up to 66 years of age, 26 women and 19 men.

After learning about the nature of the research, the participants signed a consent form for participation in the examination. The criteria for the diagnosis of glossodynia and glossopyrosis were as follows: 1) the sensation of burning of the tongue or part of the oral cavity with the presence of some local factors, such as changing the sense of taste for a long period of time; 2) normal oral cavity and tongue without any lesions; and 3) the absence of any local or systemic factors that produce the same symptoms. Criteria for exclusion from the study were persons under the age of 18, pregnant women, smokers, patients with systemic diseases and patients with oral lesions in their mouths for any reason.

Regarding the quality of life, each patient was asked to evaluate the quality of life from 0 to 10 . They were examined before the therapy and at the end of the laser therapy (on the 10th day), using a $10 \mathrm{~cm}$ Visual Analogue Scale (VAS) which goes with values from 0 to 10 (where 0 represents the absence of any symptoms that can lead to deterioration of quality of life and 10 which presents the most difficult sensations that endanger the quality of life of the respondents). Validity and reliability of VAS are well established [15].
All patients, according to the protocol, passed all necessary laboratory tests with mandatory taking anamnesis and clinical examination of the oral cavity. From laboratory findings, blood count, sedimentation, blood sugar level, and swipe tongue were used to determine the presence of fungi and bacteriological findings with the antibiogram. After obtaining the results of the analysis, the patients were treated on the basis of anamnestic data, clinical findings, and laboratory tests.

26 patients, who were randomly selected, in addition to routine treatment on the basis of history, were also treated with low-level laser. Laser therapy was done using the KaVo MASTER lase Biberach, Germany, with a wavelength of 980 $\mathrm{nm}$ with a $0.2 \mathrm{~W}$ output power in continuous mode. The parameters for the therapy were determined based on the patient's condition and the manufacturer's recommendations. For the analgesic effect in the treatment of glossopyrosis and glossodynias, the laser radiation power of $35 \mathrm{~J} / \mathrm{cm}^{2}$ was used, while the laser time was $90 \mathrm{sec}$ for 10 days $(5+5$ days $)$ with a total radiation dose of $100 \mathrm{~J} / \mathrm{cm}^{2}$.

The dorsal surface of the tongue was treated with a longer time interval of the laser beam in places where the patient feels the strongest burning, annealing, and pain. Laser treatment was performed daily to symptom loss, with a maximum of 10 sessions. In the course of laser treatment, all patients wore protective glasses to protect their eyes from possible injuries with the laser beam.

\section{Statistical analyses}

The data were analyzed using the SPSS 17 software package for Windows (SPSS, Inc., Chicago, IL). Parameters are calculated as the mean value and standard deviation. For independent samples, Student's t-test was used to determine the existence of a statistically significant difference in the values for both groups. Pearson's $\chi^{2}$ test was used to compare nonparametric testing. The results are tabulated, and the statistical significance is defined with $\mathrm{p}<0.05$.

\section{Results}

All patients in the study underwent symptomatic therapy and symptomatic therapy with the addition of lasers, and on the basis of clinical and laboratory findings, local factors were also rehabilitated (treatment of periodontal disease, sharpening of sharp edges of the teeth, repair of the carotid teeth, teeth extraction, etc.) and control of general habits and factors (blood sugar level control, anemia treatment, use of anti-fungicide and antibiotics).

The results of the work are shown in the tables. From Table 1 it can be seen that there were 45 examined patients with an average age of $46.5 \pm 2.8$ years, 19 men and 26 women. Table 2 shows the most common clinical conditions in examined patients. Table 3 shows the clinical findings of lashed patients. The laser treatment of the selected 26 patients was performed daily until the loss of symptoms of burning and pain or until reducing the symptoms that are tolerable to the patient. Table 4 shows the reduction of symptoms per day during lasers.

From Table 4 it can be seen that out of 26 patients, ten gave positive results by suggesting that the subjective feeling of 
burning and annealing decreases and make them feel more comfortable by continuing further therapy.

Table 1. Number of examined patients.

\begin{tabular}{|l|l|l|l|l|}
\hline & number $(\mathbf{n})$ & $\begin{array}{l}\text { men mean } \mathbf{\pm} \\
\text { SD }\end{array}$ & $\begin{array}{l}\text { women } \\
\text { mean } \pm \text { SD }\end{array}$ & $\mathbf{p}$ value \\
\hline age & $46.5 \pm 2.8$ & $45.3 \pm 5.2$ & $47.6 \pm 3.8$ & $p<0.6$, n.s. \\
\hline Th+laser & 26 & 10 & 16 & $p=0.8$, n.s. \\
\hline Th & 19 & 9 & 10 & $p<0.9$, n.s. \\
\hline total & 45 & 19 & 26 & \\
\hline
\end{tabular}

Table 2. Clinical findings of the respondents.

\begin{tabular}{|l|l|}
\hline Clinical condition & $\begin{array}{l}\text { Number } \\
\text { of } \\
\text { patients }\end{array}$ \\
\hline No change & 8 \\
\hline Developmental anomalies (lingua plicata et geographica) & 6 \\
\hline Anemia & 7 \\
\hline Candida infection & 6 \\
\hline Bacterial infection (Staphylococcus, E. Coli etc.) & 2 \\
\hline Coated language (smokers) & 7 \\
\hline Galvanic battery & 5 \\
\hline Cardiac patients with multiple drugs & 6 \\
\hline Diabetes mellitus & 3 \\
\hline Astmathic patients with inhalation pump application & 2 \\
\hline Dysgeusia & 3 \\
\hline
\end{tabular}

Table 3. Clinical finding of lasified patients.

\begin{tabular}{|l|l|l|l|l|l|l|l|}
\hline & $\begin{array}{l}\text { numbe } \\
\mathbf{r}(\mathbf{n})\end{array}$ & $\begin{array}{l}\text { no } \\
\text { chang } \\
\text { es }\end{array}$ & $\begin{array}{l}\text { Develop. } \\
\text { anomalie } \\
\mathbf{s}\end{array}$ & $\begin{array}{l}\text { Diabete } \\
\mathbf{s} \\
\text { mellitu } \\
\mathbf{s}\end{array}$ & $\begin{array}{l}\text { Candid } \\
\text { a }\end{array}$ & $\begin{array}{l}\text { Anecteri } \\
\text { al } \\
\text { ia } \\
\text { infecti } \\
\text { on }\end{array}$ \\
\hline men & 10 & 2 & 1 & 1 & 3 & 2 & 1 \\
\hline $\begin{array}{l}\text { wome } \\
n\end{array}$ & 16 & 3 & 3 & 2 & 4 & 3 & 1 \\
\hline
\end{tabular}

Table 4. Reduction of symptoms in patients treated with laser.

\begin{tabular}{|l|l|l|l|l|l|l|l|l|l|l|}
\hline Number of patients & \multicolumn{6}{|c|}{ number of days treated with laser } \\
\hline & 1 & 2 & 3 & 4 & 5 & 6 & 7 & 8 & 9 & 10 \\
\hline 1 & - & - & - & - & - & - & - & - & - & - \\
\hline 2 & + & + & + & + & - & - & + & - & - & + \\
\hline 3 & - & - & + & + & + & + & + & + & + & $/$ \\
\hline 4 & - & - & + & + & + & + & + & + & $/$ & $/$ \\
\hline 5 & - & - & + & + & + & + & + & + & $/$ & $/$ \\
\hline 6 & - & + & + & + & + & + & + & + & $/$ & $/$ \\
\hline 7 & + & + & + & + & - & - & + & + & - & + \\
\hline 8 & - & + & + & + & + & + & + & + & + & + \\
\hline
\end{tabular}

\begin{tabular}{|l|l|l|l|l|l|l|l|l|l|l|}
\hline 9 & - & + & + & + & + & + & $/$ & $/$ & $/$ & $/$ \\
\hline 10 & - & - & + & + & + & + & $/$ & $/$ & $/$ & $/$ \\
\hline 11 & - & - & + & + & + & + & $/$ & $/$ & $/$ & $/$ \\
\hline 12 & - & - & - & - & - & - & - & - & - & - \\
\hline 13 & + & - & - & - & + & + & + & $/$ & $/$ & $/$ \\
\hline 14 & - & - & + & + & + & - & - & + & + & + \\
\hline 15 & + & + & + & + & - & - & + & - & + & - \\
\hline 16 & - & - & - & - & - & + & + & + & + & + \\
\hline 17 & - & - & - & - & - & - & - & - & - & - \\
\hline 18 & - & - & + & + & + & + & + & $/$ & $/$ & $/$ \\
\hline 19 & - & - & - & - & + & + & + & + & $/$ & $/$ \\
\hline 20 & - & - & - & + & + & + & + & + & - & - \\
\hline 21 & - & - & - & - & + & + & + & + & + & + \\
\hline 22 & - & - & - & - & - & - & - & - & - & - \\
\hline 23 & + & + & + & + & + & + & $/$ & $/$ & $/$ & $/$ \\
\hline 24 & + & + & + & + & + & + & $/$ & $/$ & $/$ & $/$ \\
\hline 25 & - & - & - & + & + & + & $/$ & $/$ & $/$ & $/$ \\
\hline 26 & - & - & - & + & + & + & - & - & + & + \\
\hline
\end{tabular}

Three patients, out of 26 treated with lasers, after the fourth day of laser therapy showed that the symptoms of burning and annealing were reduced, but after the 5th and 6th day of laser therapy, their original problem was still present, and these are permanent salty taste in the mouth, dryness, and tonguetwisting. Their disorder has a psychological background with the appearance of dysgeusia. After the sixth day of radiation and visual improvement in symptoms, six patients did not apply for further therapy. After the eighth day of radiation with the loss of severe burning symptoms, there were 4 patients, after the ninth radiation 1 , while 8 patients were treated for 10 days with the statements that the sensations are much less and tolerant to life. Four patients did not even feel a decrease in the feeling of burning and pain in the tongue after 10 days of laser therapy.

As shown in Table 5, after the completion of therapy with the addition of a low-level laser, there was a statistically significant decrease in the symptoms of dynia and pyrosis, which resulted in the improvement of the quality of life of the patients who participated in this study $(\mathrm{p}<0.001)$.

Table 5. Visual analog scale for the feeling of subjective symptoms that affect the quality of life of the respondents before and after the therapeutic procedure.

\begin{tabular}{|l|l|l|l|l|}
\hline & $\begin{array}{l}\text { number } \\
\text { (n) }\end{array}$ & $\begin{array}{l}\text { before therapy } \\
\text { mean } \pm \text { SD }\end{array}$ & $\begin{array}{l}\text { after therapy } \\
\text { mean } \pm \text { SD }\end{array}$ & p-value \\
\hline th+laser & 26 & $207 \pm 28.6$ & $77 \pm 12.4$ & $\begin{array}{l}p<0,00 \\
1\end{array}$ \\
\hline th & 19 & $141 \pm 15.3$ & $51 \pm 9.3$ & $\begin{array}{l}p=0.6 \\
\text { n.s. }\end{array}$ \\
\hline
\end{tabular}




\section{Discussion}

Glossodyniae and glossopyrosis have complex etiology [16]. The cause may be local (xerostomia, stomatitis, candidosis, destroyed teeth, developmental anomalies, periodontal disease, etc.), systemic (pernicious anemia, arteriosclerosis, cardiovascular diseases, neurohormonal imbalance, diabetes, etc.) or psychological (hypochondriasis, depression, cancerophobia, etc.) [4]. Many studies have examined the function of psychological factors in the onset of burning and pain when there are no clinical changes in the tongue (atrophy, erosion, or ulcer), while usually easy to cure code patients with changes in the mouth [17].

Therapy becomes even more complicated if the symptoms do not decrease after the basic treatment (denture correction, caries, and periodontal surgery, etc.) and laboratory testing (microbiological tests for the presence of fungi and complete hematological examination).

Based on the results shown, it can be clearly seen that lowlevel laser therapy with its analgesic effect significantly reduces the burning sensation of patients with diagnosed glossopyrosis and glossodynia.

All lashed patients had a burning, and painful feeling, or even a sense of salty taste before starting a laser radiation regimen, even after remediation of possible local and general symptoms. No subjects were used in the study, in order to avoid the potentiating effect of the sedative on the analgesic effect of the laser.

Low-level lasers have an anti-inflammatory, antiedematous, stimulating and analgesic effect. In patients in this investigation, the ability of a low-level laser to modify the "feeling" of pain was used because burning is considered to be the smallest feeling of pain $[18,19]$.

Emotional and effective pain perception is related to the activity of the bark of the big brain. There are many theories of pain, so the analgesic action of lasers is still in the phase of presumption [11]. For the physiology of pain of special significance are the chemical mediators of the transmission of the nerve impulse, i.e. neurotransmitters. A particularly important group of neurotransmitters, i.e. neuropeptides, for the physiology of pain are endogenous opiates: enkephalin and endorphins. They exhibit effects similar to that of morphine and other opiates [20,21].

Experimental data indicate that during the treatment of pain, a low-level laser results in the release of endorphins and encephalin, which is accompanied by a reduction in pain sensitivity. These opiates prevent the release of the so-called R-specific neuropeptide R substance in the CNS, which has the role of pain transmission. The discontinued release of the substance R "closes the gate" for the passage of painful information into the CNS, causing an analgesic effect. All of this may have to do with a low-level laser [21]. Of course, reducing edema during treatment with a low-level laser can lead to pain reduction. Pain reduction by low-level laser therapy can have an effect and stabilization of the membrane of the nerve cells, making the transamination of pain more difficult at the local level [11,22]. All these mechanisms of transmission and interruption of pain should be further considered within the framework of laser therapy and their application in the treatment of painful diseases of the mucous membrane of the lobe of the cavity.

The results of this study on the low-power analgesic effect of low-laser therapy are consistent with the findings of other authors who examined the analgesic action of lasers in the treatment of mucous membrane-related diseases (aphthae, herpes, etc.) [14,18,20,23].

\section{Conclusion}

According to the results of this study, and based on the patient's testimony, the low-level laser can be used as an additional method of treatment in reducing painful sensationsburning and annealing, in patients with glossopyrosis and glossodynia.

Applying low-level laser therapy, although it cannot cure the causes of dynia and pyrosis, it can, by reducing pain sensations, improve the quality of life of patients who have these symptoms.

\section{References}

1. Dutree-Meulenberg RPGM, Kozel MMA, van Joost T. Burning mouth syndrome: A possible etiologic role for local contact hypersensitivity. Journal of the American Academy of Dermatology. 1992; 26: 935-940.

2. Huang W, Rothe MJ, Grant-Kels JM. The burning mouth syndrome. Journal of the American Academy of Dermatology. 1996; 34: 91-98.

3. Helton J, Storrs F. The burning mouth syndrome: lack of a role for contact urticaria and contact dermatitis. Journal of the American Academy of Dermatology. 1994; 31: 201-205.

4. Orlov S, Mirković B, et al. Oral medicine. Sitomehanika, Niš 2007

5. Aggarwal A, Panat SR. Burning mouth syndrome: A diagnostic and therapeutic dilemma. Journal of Clinical and Experimental Dentistry. 2012; 4: 180-185.

6. Terai H, Shimahara M. Tongue pain: burning mouth syndrome vs Candida-associated lesion. Oral Diseases. 2007; 13: 440-442.

7. Romeo U, Del Vecchio A, Capocci M, Maggiore C, Ripari M The low-level laser therapy in the management of neurological burning mouth syndrome. A pilot study. Annali di stomatologia (Romanian). 2010; 1: 14-18.

8. Heckmann SM, Kirchner E, Grushka M, Wichmann MG, Hummel T. A double-blind study on clonazepam in patients with burning mouth syndrome. Laryngoscope. 2012; 122: 813-816.

9. Guarneri F, Guarneri C, Marini H. Contribution of neuroinflammation in burning mouth syndrome: indications from benzodiazepine use. Dermatologic Therapy. 2008; 21: 21-24.

10. Pezelj-Ribarić S, Kqiku L, Brumini G, Urek MM, Antonić R, et al. Proinflammatory cytokine levels in saliva in patients with burning mouth syndrome before and after treatment with low-level laser therapy. Lasers in Medical Science. 2013; 28: 297-301.

11. Pejčić A. Comparative analysis of low-level laser therapy and conservative therapy of inflamed gingiva. Master thesis. Medical faculty, Niš, 2005

12. Jugomir S, Stipančić M. Laser. Sarajevo, Svjetlost. 1977.

13. Tarasov L. Lasers Physics and applications. Moscow, Mir publishers. 1986.

14. Čowagmičiska L, Uranov C. Proučavane na vlienieto na helio-neonovu lozer vrhu noličuestvenite iymenini na microflorato $\mathrm{v}$ 
parodontalnijo džob pri bolni s hemoragizna parodontoza. Stomatologiia. 1988; 5: 27-31.

15. Bijur PE, Silver W, Gallagher EJ. Reliability of the visual analog scale for measurement of acute pain. Academic Emergency Medicine. 2001; 8: 1153-1157.

16. Perno M. Burning mouth syndrome. Journal of Dental Hygiene. 2001; 75: 245-252.

17. Mignogna MD, Fedele S, LoRusso L, Leuci S. The diagnosis of burning mouth syndrome represents a challenge for clinicians. The Journal of Oral and Facial Pain. 2005; 19: 168-173.

18. Han JC. High and low-frequency electroacupuncture analgesia are mediated by different peptides. Pain. 1984; 2: 543-548.

19. Maričić B, Mady L, Hraste J, Zuza B. The analgesic effect of lasers in dental therapy. Acta stomatologica Croatica. 1987; 21: 291-302.
20. Walker JB, Akhanzee K. Laser-induced Somatosenzory evoked potential: Evidence of photosensitivity in peripheral nervs. Brain Research. 1989; 344: 281-285.

21. Han JC. Biogenesis, release and degradation of endogenous opiales. The Journal of Physiological Sciences. 1984; 15: 107-110.

22. Stanković I, Milić H, Stefanović S. Low power laser in therapy of cervical myofascal pain. Acta Facultatis Medicae Naissensis. 1999; 16: 205-208.

23. Trojančanec Z. Biostimulirački laseron homedicinato. ANS Kompjuteri-DeskTop, Skopje. 1995. 